\title{
Identification of lung cancer oncogenes based on the mRNA expression and single nucleotide polymorphism profile data
}

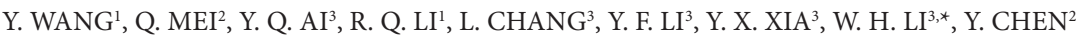 \\ ${ }^{1}$ Department of Radiation Oncology, The First affiliated hospital of Kunming medical university, Kunming, 650032, China; ${ }^{2}$ Department of \\ Oncology, Tongji Hospital, Tongji Medical College, Huazhong University of Science and Technology, Wuhan, 430030, China; ${ }^{3}$ Cancer Radio- \\ therapy Research Center, The Third affiliated Hospital, Kunming Medical University, Kunming, 650118, China
}

${ }^{*}$ Correspondence: wenhuiliwhl@163.com

Received March 15, 2015 / Accepted June 17, 2015

\begin{abstract}
This study aimed to identify the oncogenes associated with lung cancer based on the mRNA and single nucleotide polymorphism (SNP) profile data. The mRNA expression profile data of GSE43458 (80 cancer and 30 normal samples) and SNP profile data of GSE33355 (61 pairs of lung cancer samples and control samples) were downloaded from Gene Expression Omnibus database. Common genes between the mRNA profile and SNP profile were identified as the lung cancer oncogenes. Risk subpathways of the selected oncogenes with the SNP locus were analyzed using the iSubpathwayMiner package in R. Moreover, protein-protein interaction (PPI) network of the oncogenes was constructed using the HPRD database and then visualized using the Cytoscape. Totally, 3004 DEGs (1105 up-regulated and 1899 down-regulated) and 125 significant SNPs closely related to 174 genes in the lung cancer samples were identified. Also, 39 common genes, like PFKP (phosphofructokinase, platelet) and DGKH-rs11616202 (diacylglycerol kinase, eta) that enriched in sub-pathways such as galactose metabolism, fructose and mannose metabolism, and pentose phosphate pathway, were identified as the lung cancer oncogenes. Besides, PIK3R1 (phosphoinositide-3-kinase, regulatory subunit 1), RORA (RAR-related orphan receptor A), MAGI3 (membrane associated guanylate kinase, WW and PDZ domain containing 3), PTPRM (protein tyrosine phosphatase, receptor type, M), and BMP6 (bone morphogenetic protein 6) were the hub genes in PPI network. Our study suggested that PFKP and DGKH that enriched in galactose metabolism, fructose and mannose metabolism pathway, as well as PIK3R1, RORA, and MAGI3, may be the lung cancer oncogenes.
\end{abstract}

Key words: lung cancer, single nucleotide polymorphism (SNP), function analysis, differentially expressed gene, oncogenes

Lung cancer is one of the most common malignancies with an increasing morbidity and mortality and is a worldwide leading cause of cancer-related death with a 5-year survival rate from $13 \%$ to $15 \%$ [1]. Mechanism of lung cancer is complicate, mainly due to the late diagnosis and lack of effective treatment [2]. Therefore, underlying the molecular profiles of lung cancer as well as elucidating the roles of oncogenes and tumor suppressors in the development of this malignancy is expected to identify the molecular targets for lung cancer prediction and treatment.

Previous studies have demonstrated that environmental factors like smoking and air pollution, and gene polymorphisms were the main factors contributing to the lung cancer progres-

\footnotetext{
Abbreviations: SNP - single nucleotide polymorphism; PPI - proteinprotein interaction; DEGs - differentially expressed genes
}

sion and metastasis [3]. Chemical constituents in tobacco smoke including compounds of the carcinogenic polycyclic type were the carcinogen for lung cancer [4]. A previous study reveals that mutations of the tumor suppressor genes are a main reason for lung cancer progression, such as the prevalence of p53 mutational patterns $\mathrm{G}$ to $\mathrm{T}$ transversions is $30 \%$ and p53 mutations in lung cancer can be attributed to the direct DNA damage [5]. Besides, increasing evidences have demonstrated that genes with single nucleotide polymorphism (SNP) played crucial roles in many cancers $[6,7]$. For instance, rs1051730 and rs8034191 that map to the region of 15q25.1 containing PSMA4 (proteasome alpha 4 subunit isoform 1) and the nicotinic acetylcholine receptor gene CHRNA3 and CHRNA5 (nicotinic acetylcholine receptor alpha subunits 3 and 5), are related to the lung cancer risk [8]. Also, variations of TERT(rs2736100)-CLPTM1L(rs4975616) and CHRNA5- 
CHRNA3 (rs8042374) influence the risk of lung cancer in non-smokers [9].

Lai et al. [10] using the GSE33355 microarrays to study that SNP rs10248565 in HDAC9 was a novel genomic aberration biomarker of lung adenocarcinoma in non-smoking women. Chan et al. [11] used the GSE43458 microarrays to construct the molecular probes for lung cancer, while Kabbout et al. [12] proved the suppression role of ETS2 in human non-small lung cancer cells by inhibiting of the MET proto-oncogene using the same profile data. In this study, we used the microarray analysis to screen the differentially expressed genes (DEGs) in lung cancer based on the mRNA microarray GSE43458 and SNP microarray GSE33355. Comprehensive bioinformatics was used to construct the protein-protein interaction (PPI) network and to select the risk subpathways of the DEGs to investigate the functions and pathways of hub genes associated with lung cancer. Our study aims to select several key oncogenes in lung cancer and provide theoretical basis for the lung cancer treatment.

\section{Materials and methods}

Data resources and data preprocessing. The mRNA expression profile data of GSE43458 [12], including 80 lung cancer samples and 30 normal samples, was downloaded from the GEO (Gene Expression Omnibus) database in NCBI (National Center for Biotechnology Information) (http://www. ncbi.nlm.nih.gov/geo/) based on the platform of GPL6244 [HuGene-1_0-st] Affymetrix Human Gene 1.0 ST Array [transcript (gene) version]. The downloaded CEL files were normalized using the affy package in R [13], and 20254 probes were obtained after normalization.

In addition, the SNP microarray data of GSE33355 [14], containing 61 lung cancer samples and 61 normal samples from non-smoking females, was downloaded from the GEO database in NCBI based on the platform of GPL6801 [GenomeWideSNP_6] Affymetrix Genome-Wide Human SNP 6.0 Array. The downloaded SNP files were subtyped using the crlmm package [15], hapmapsnp package [16], and pd.genomewidesnp.6 package [17] in R language to eliminate the samples with subtyped success rate lower than $90 \%$. Finally, 118 samples (60 lung cancer samples and 58 controls) with 847,576 probes were chosen in this study.

Screening of DEGs and significant SNPs. The DEGs in the lung cancer samples compared to the controls were screened using the limma package in $\mathrm{R}$ [18]. The t-test and Bonferroni test [19] were used to adjust the p-value of each gene. The adj.p-value $<0.05$ and $\mid \log 2$ FC (fold change) $\mid>0.5$ were chosen as the threshold. Additionally, plink software is a tool set for whole-genome association and population-based lingage analyses [20]. The assoc in plink [21] was used to select the significant SNPs in lung cancer samples compared with the controls with the p-vaule $<0.05$.

Identification of lung cancer oncogenes. In order to select the oncogenes of lung cancer, the genes that both correspond- ing to the selected significant SNPs and the selected DEGs were analyzed as the oncogenes.

Genes associated with one or more than one SNP were screened. If there was more than one SNPs for one gene, the most significant $\mathrm{p}$-value for one SNP was considered as the $\mathrm{p}$-value for one gene. The common genes were screened that both in the selected DEGs set and the gene set corresponding to the SNPs. The common genes that fit into the $\chi^{2}$ square distribution with the $2 \mathrm{~K}$ freedom degree, were tested using the Fisher's combination method [22] based on the formula of $\chi^{2}=-2 \sum_{\mathrm{i}=1}^{\mathrm{k}} \ln \mathrm{P}_{\mathrm{i}}$. Wherase, $\mathrm{K}=2, \mathrm{P}_{\mathrm{i}}$ stands for the $\mathrm{p}$-value for one common gene that associated with the p-value of this DEG as well as the significant $p$-value for this gene with the significant SNP. The $\mathrm{p}$-value $<0.05$ was chosen as the threshold.

Risk subpathways selection of the oncogenes. The pathways of the selected oncogenes were analyzed using the iSubpathwayMiner package in R [23]. The p-value $<0.05$ was chosen as the threshold.

Construction and analysis of the PPI network of the oncogenes. HPRD (Human Protein Reference Database) is a database of curated proteomic information pertaining to human proteins [24]. In order to investigate the interactions among the selected lung cancer oncogenes, PPI network of 39 oncogenes was constructed using the HPRD database and then visualized using the Cytoscape software [25]. Additionally, topological analysis of PPI network was conducted to calculate the node degree of each gene.

\section{Results}

Screening of DEGs and significant SNPs. Totally, 3004 DEGs (1105 up-regulated and 1899 down-regulated) in the lung cancer samples were screened. Also, 125 significant SNPs (that located in gene coding region, upstream and downstream control region) were identified to be associated with 174 genes in the lung cancer samples.

Risk subpathways selection of the oncogenes. A total of 39 common genes between the selected DEGs and genes associated with the significant SNPs were identified as the lung cancer oncogenes (Table 1). The risk sub-pathways of the selected oncogenes were shown in Table 2. The PFKP- rs11251105 (phosphofructokinase, platelet) and DGKH-rs11616202 (diacylglycerol kinase, eta) were 2 oncogenes that enriched in sub-pathways such as galactose metabolism, fructose and mannose metabolism, and pentose phosphate pathway, implying their important roles in lung cancer.

PPI network of the oncogenes and topological analysis. The PPI network of the selected 39 lung cancer oncogenes was constructed, including 281 nodes and 268 gene interaction pairs (Figure 1). There were 27 oncogenes and 254 nononcogenes that interacted with the selected oncogenes. The topological analysis of the PPI network showed that PIK3R1 (phosphoinositide-3-kinase, regulatory subunit 1), RORA (RAR-related orphan receptor A), MAGI3 (membrane associ- 
Table 1. The selected 39 oncogenes of lung cancer

\begin{tabular}{|c|c|c|c|c|}
\hline Gene & Limma p-value & dbsnpID & Chromosome & SNP p-value \\
\hline ADRA2A & $1.08 \mathrm{E}-06$ & rs17129502 & 10 & 0.04948 \\
\hline AGR3 & 0.003068 & rs4329181 & 7 & 0.01242 \\
\hline AGTR2 & 0.000109 & rs5950506 & $\mathrm{X}$ & 0.0474 \\
\hline BMP6 & $3.98 \mathrm{E}-16$ & rs 267203 & 6 & 0.04659 \\
\hline C10orf84 & $4.02 \mathrm{E}-10$ & rs933018 & 10 & 0.04948 \\
\hline CACNA2D1 & 0.002882 & rs37109 & 7 & 0.04548 \\
\hline CACNB4 & 0.000128 & rs 16830650 & 2 & 0.02636 \\
\hline CD180 & 2.84E-06 & rs7705112 & 5 & 0.04955 \\
\hline CLDN18 & $4.65 \mathrm{E}-10$ & rs11706173 & 3 & 0.04548 \\
\hline CNTN4 & $2.81 \mathrm{E}-19$ & rs11714941 & 3 & 0.04766 \\
\hline CRBN & $2.96 \mathrm{E}-13$ & rs13318984 & 3 & 0.04941 \\
\hline DGKH & $8.68 \mathrm{E}-07$ & rs11616202 & 13 & 0.03196 \\
\hline FGF10 & $5.35 \mathrm{E}-15$ & rs 1004720 & 5 & 0.04934 \\
\hline GRIP1 & 0.000165 & rs17779811 & 12 & 0.02771 \\
\hline IL20RB & 0.000398 & rs 16847364 & 3 & 0.01341 \\
\hline KLF4 & $1.41 \mathrm{E}-16$ & rs10119737 & 9 & 0.02925 \\
\hline LPHN3 & $2.25 \mathrm{E}-20$ & rs12510186 & 4 & 0.04955 \\
\hline LRIG1 & 0.000138 & rs9818858 & & 0.04955 \\
\hline MAGI3 & $3.14 \mathrm{E}-08$ & rs1624335 & 1 & 0.02501 \\
\hline MSRB3 & $3.52 \mathrm{E}-19$ & rs7970955 & 12 & 0.04355 \\
\hline MYH10 & $4.72 \mathrm{E}-16$ & rs6503137 & 17 & 0.02647 \\
\hline PCDH17 & $4.52 \mathrm{E}-13$ & rs7996198 & 13 & 0.03373 \\
\hline PCDH20 & 0.002186 & rs 17088665 & 13 & 0.04744 \\
\hline PCDH9 & $4.88 \mathrm{E}-05$ & rs17078274 & 13 & 0.0291 \\
\hline PFKP & $5.00 \mathrm{E}-07$ & rs11251105 & 10 & 0.04927 \\
\hline PIK3R1 & $6.53 \mathrm{E}-10$ & rs7705112 & 5 & 0.04955 \\
\hline PIP5K1B & $6.92 \mathrm{E}-15$ & rs 1576586 & 9 & 0.04941 \\
\hline PTPRM & $2.22 \mathrm{E}-15$ & rs16953828 & 18 & 0.02144 \\
\hline RGS6 & 0.0014 & rs8011978 & 14 & 0.03963 \\
\hline RORA & 4.52E-09 & rs8039843 & 15 & 0.04365 \\
\hline $\mathrm{RP} 1$ & $3.85 \mathrm{E}-09$ & rs4737807 & 8 & 0.0417 \\
\hline S1PR1 & $1.19 \mathrm{E}-24$ & rs11164248 & 1 & 0.03042 \\
\hline SEMA6A & $2.49 \mathrm{E}-20$ & rs684730 & 5 & 0.04744 \\
\hline SLC16A7 & 0.00427 & rs3763979 & 12 & 0.04747 \\
\hline SLC1A1 & $3.81 \mathrm{E}-09$ & rs4376542 & 9 & 0.04175 \\
\hline SMARCA2 & $1.18 \mathrm{E}-06$ & rs942400 & 9 & 0.0474 \\
\hline SOX5 & 3.49E-15 & rs7967757 & 12 & 0.01878 \\
\hline TNR & $4.44 \mathrm{E}-12$ & rs10798415 & 1 & 0.04167 \\
\hline ZNF521 & 3.63E-07 & rs1674614 & 18 & 0.04546 \\
\hline
\end{tabular}

Limma p-value: the p-value of one oncogene analyzed in the mRNA expression profile; SNP p-value: the p-value of one oncogene analyzed in the SNP data.

ated guanylate kinase, WW and PDZ domain containing 3), AMARCA2, PTPRM (protein tyrosine phosphatase, receptor type, M), and BMP6 (bone morphogenetic protein 6) were the genes with top 5 node degree (Table 3 ).

\section{Discussion}

In this study, we used the mRNA expression profile and the SNP profile to select the oncogenes of lung cancer. PFKP-rs11251105 and DGKH-rs11616202 that enriched in sub-pathways such as galactose metabolism, fructose and mannose metabolism, and pentose phosphate pathway, were identified as the lung cancer oncogenes. Besides, PIK3R1rs7705112, RORA-rs8039843, and MAGI3-rs1624335 were the hub genes in PPI network.

Our findings displayed that PFKP-rs11251105 and DG$\mathrm{KH}-\mathrm{rs} 11616202$ were the two oncogenes enriched in the risk sub-pathways galactose metabolism, fructose and mannose metabolism, and pentose phosphate pathway, suggesting their important roles in lung cancer. PFKP (encoded by 
Table 2. The risk sub-pathways of selected oncogenes

\begin{tabular}{|c|c|c|c|}
\hline PathwayID & pathwayName & pvalue & Genes \\
\hline path:00052_2 & Galactose metabolism & 0.006591 & PFKP \\
\hline path:00052_4 & Galactose metabolism & 0.006591 & PFKP \\
\hline path:00052_8 & Galactose metabolism & 0.006591 & PFKP \\
\hline path:00052_1 & Galactose metabolism & 0.008232 & PFKP \\
\hline path:00052_6 & Galactose metabolism & 0.019646 & PFKP \\
\hline path:00051_10 & Fructose and mannose metabolism & 0.022884 & PFKP \\
\hline path:00010_5 & Glycolysis / Gluconeogenesis & 0.029328 & PFKP \\
\hline path:00010_7 & Glycolysis / Gluconeogenesis & 0.030932 & PFKP \\
\hline path:00051_3 & Fructose and mannose metabolism & 0.030932 & PFKP \\
\hline path:00010_2 & Glycolysis / Gluconeogenesis & 0.032534 & PFKP \\
\hline path:00051_8 & Fructose and mannose metabolism & 0.032534 & PFKP \\
\hline path:00051_15 & Fructose and mannose metabolism & 0.032534 & PFKP \\
\hline path:00010_6 & Glycolysis / Gluconeogenesis & 0.034134 & PFKP \\
\hline path:00051_2 & Fructose and mannose metabolism & 0.034134 & PFKP \\
\hline path:00051_6 & Fructose and mannose metabolism & 0.035731 & PFKP \\
\hline path:00030_1 & Pentose phosphate pathway & 0.038917 & PFKP \\
\hline path:00030_2 & Pentose phosphate pathway & 0.038917 & PFKP \\
\hline path:00030_3 & Pentose phosphate pathway & 0.043676 & PFKP \\
\hline path:00561_5 & Glycerolipid metabolism & & DGKH \\
\hline path:00561_1 & Glycerolipid metabolism & & DGKH \\
\hline path:00561_2 & Glycerolipid metabolism & 0.079414 & DGKH \\
\hline path:00564_5 & Glycerophospholipid metabolism & 0.079414 & DGKH \\
\hline path:00564_9 & Glycerophospholipid metabolism & 0.079414 & DGKH \\
\hline path:00564_2 & Glycerophospholipid metabolism & 0.091538 & DGKH \\
\hline path:00564_3 & Glycerophospholipid metabolism & 0.096044 & DGKH \\
\hline path:00564_8 & Glycerophospholipid metabolism & 0.096044 & DGKH \\
\hline path:00564_1 & Glycerophospholipid metabolism & 0.099036 & DGKH \\
\hline path:00564_6 & Glycerophospholipid metabolism & 0.099036 & DGKH \\
\hline path:00564_7 & Glycerophospholipid metabolism & 0.099036 & DGKH \\
\hline path:00564_10 & Glycerophospholipid metabolism & 0.100529 & DGKH \\
\hline
\end{tabular}

PFKP gene) is a platelet isoform of phosphofructokinase that catalyzes the irreversible conversion of fructose-6-phosphate to fructose-1,6-bisphosphate and is a key regulator enzyme in glycolysis [26], while DGKH (encoded by DGKH gene) is a member of the diacylglycerol kinase enzyme family of proteins that are involved in regulating the intracellular concentrations of diacylglycerol and phosphatidic acid [27]. Roles of DGKH and PFKP in lung cancer have not been fully discussed. However, Oparina et al. proved that expression stability of the glycolytic enzyme encoding genes affecting the malignant and mRNA expression level of PFKP in kidney cancer was higher than the normal samples [28]. Molatore and his colleagues proved that DGKH was up-regulated in rats with pheochromocytoma and may be a biomarker for clinical use [29]. Thus, PFKP and DGKH may be important in lung cancer development. Besides, previous study has referred that due to high consumption of dairy foods or reduced galactose metabolism, increasing exposure to galactose was related to the ovarian cancer development [30]. Also, Tachibana et al. proved the association between
Table 3. The selected oncogenes with top 5 node degree in PPI network

\begin{tabular}{lc}
\hline Gene & Node degree \\
\hline MYH10 & 5 \\
SEMA6A & 5 \\
KLF4 & 6 \\
TNR & 6 \\
CACNB4 & 7 \\
S1PR1 & 7 \\
ADRA2A & 8 \\
AGTR2 & 8 \\
GRIP1 & 8 \\
BMP6 & 9 \\
PTPRM & 9 \\
SMARCA2 & 11 \\
MAGI3 & 12 \\
RORA & 15 \\
PIK3R1 & 127 \\
\hline
\end{tabular}




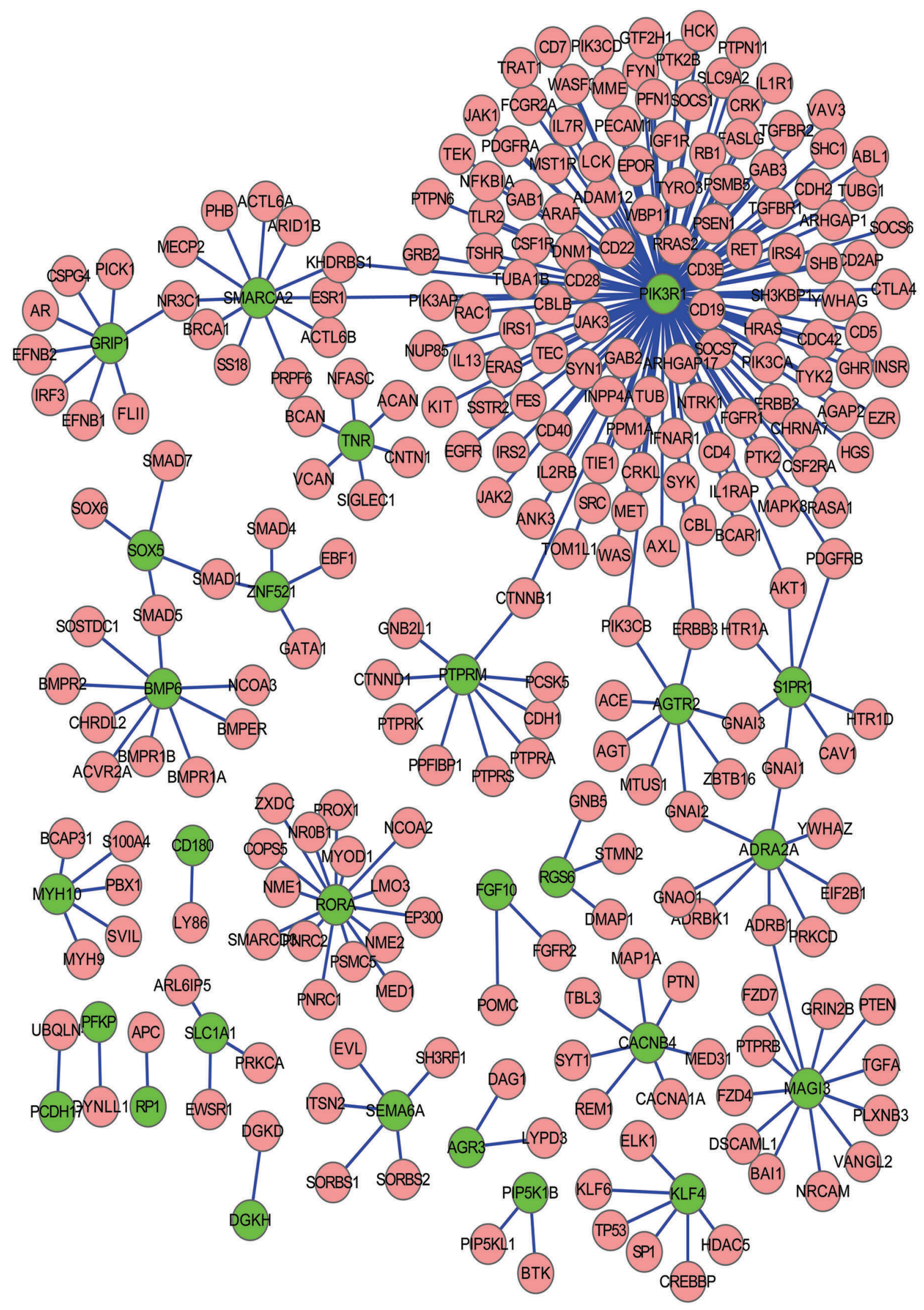

Figure 1. Protein-protein interaction network of the lung cancer oncogenes

Green nodes represent the lung cancer oncogenes and red nodes represent the non-oncogenes that interacted with the lung cancer oncogenes. 
fructose and lung cancer [31]. Martin et al. said that the glycolysis pathways and the enzymes were up-regulated in non-small cell lung cancer cells [32]. Based on our study, we speculated that PFKP and DGKH maybe two oncogenes contributing to the lung cancer development via involving in the galactose metabolism, fructose and mannose metabolism.

PIK3R1 (encoded by PIK3R1 gene), also known as GRB1, p85-ALPHA, is a regulatory subunit that plays an important role in the metabolic actions of insulin and is related to protein phosphatase binding [33]. Overexpression of PIK3R1 was involved in the SRSF2 RNA expression in H358 lung cancer [34]. Also, PIK3R1 that associated with the cell apoptosis, was overexpressed in non-small cell lung cancer [35]. Mutation of PIK3R1 has been observed in the thyroid cancer [36], ovarian and breast cancer [37], and the PIK3R1 3'untranslated region was the binding site for miR-127-3p including SNP-56 in bladder cancer [38]. Our data showed that down-regulated PIK3R1 with the SNP-rs7705112 was the hub protein in PPI network, suggesting its promoter role in lung cancer.

RORA (encoded by RORA gene) is a member of the NR1 subfamily of nuclear hormone receptors [39]. RORA binds to the promoter region of let-7a2 gene in lung cancer A549 cells [40]. Shi et al. said that silencing of RORA attenuated the cell apoptosis while overexpression of RORA enhanced the cell apoptosis in patients with pulmonary emphysema [41]. Also, role of RORA associated with $\mathrm{T}$ cell cytokines in the non-small cell lung cancer was also performed by Neurath [42]. Hence. RORA may be a contributor in lung cancer development. Our findings displayed that RORA was the hub protein in the PPI network, indicating that RORA may be an oncogene in lung cancer development.

Meanwhile, MAGI3 is a protein that function as a scaffolding protein at cell-cell junctions, thereby regulating various cellular and signaling processes [43]. It has been reported that MAGI3 could cooperate with PTEN to modulate the AKT1 activity $[44,45]$. Tang et al. proved that the overexpression of AKT1 and loss expression of PTEN (phosphatase and tensin homolog) in non-small cell lung cancer resulted to a poor prognosis [46]. Therefore, MAGI3 may be important in lung cancer prognosis. Also, role of MAGI3 in lung cancer via the WNT/PCP signaling pathway has been reported from the study of Katoh et al. [47]. In this study, the MAGI3 was the hub protein in the PPI network, implying that MAGI3 may be an oncogene in lung cancer prognosis.

In conclusion, our study attempted to investigate several crucial genes with SNPs that associated with the mechanism of lung cancer. PFKP and DGKH that enriched in galactose metabolism, fructose and mannose metabolism pathway, and PIK3R1, RORA, and MAGI3, may be the lung cancer oncogenes. Our study may provide basis for the lung cancer mechanism research. However, further experimental studies on these selected oncogenes are still needed since our findings were based only on the microarray data downloaded from GEO database.
Acknowledgements: This work was supported by Hubei Provincial Natural Science Foundation of China No. 2014CFB366.

\section{References}

[1] SIEGEL R, MA J, ZOU Z, JEMAL A. Cancer statistics, 2014. CA: a cancer journal for clinicians 2014; 64: 9-29. http:// dx.doi.org/10.3322/caac. 21208

[2] SINGH CR, KATHIRESAN K. Molecular understanding of lung cancers-A review. Asian Pacific journal of tropical biomedicine 2014; 4: S35. http://dx.doi.org/10.12980/ APJTB.4.2014C597

[3] HIRVONEN AP. Lung Cancer: Genetic Susceptibility. Springer, 2014: 231-241.

[4] DEVESA SS, BRAY F, VIZCAINO AP, PARKIN DM. International lung cancer trends by histologic type: male: female differences diminishing and adenocarcinoma rates rising. International journal of cancer 2005; 117: 294-299. http:// dx.doi.org/10.1002/ijc.21183

[5] KERSTING M, FRIEDL C, KRAUS A, BEHN M, PANKOW $\mathrm{W}$, et al. Differential frequencies of p16INK4a promoter hypermethylation, p53 mutation, and K-ras mutation in exfoliative material mark the development of lung cancer in symptomatic chronic smokers. Journal of clinical oncology 2000; 18: 3221-3229.

SCHWARTZBERG L, SONIS S, WALKER M, WEIDNER $S$, ALTEROVITZ G. Single nucleotide polymorphism (SNP) Bayesian networks (BNs) predict risk of chemotherapy-induced side effects in patients with breast cancer receiving dose dense (DD) Doxorubicin/cyclophosphamide plus paclitaxel (AC+ T). Cancer Res 2012; 72: P1-15-12.

[7] TSUCHIYA N, MATSUI S, NARITA S, KAMBA T, MITSUZUKA K, et al. Distinct cancer-specific survival in metastatic prostate cancer patients classified by a panel of single nucleotide polymorphisms of cancer-associated genes. Genes \& cancer 2013: 1947601913481354. http://dx.doi. org/10.1177/1947601913481354

[8] AMOS CI, WU X, BRODERICK P, GORLOV IP, GU J, et al. Genome-wide association scan of tag SNPs identifies a susceptibility locus for lung cancer at $15 \mathrm{q} 25.1$. Nature genetics 2008; 40: 616-622. http://dx.doi.org/10.1038/ng.109

[9] WANG Y, BRODERICK P, MATAKIDOU A, EISEN T, HOULSTON RS. Role of 5p15. 33 (TERT-CLPTM1L), 6 p21. 33 and 15q25. 1 (CHRNA5-CHRNA3) variation and lung cancer risk in never smokers. Carcinogenesis 2009: bgp287.

[10] LAI L-C, TSAI M-H, CHEN P-C, CHEN LH, HSIAO J-H, et al. SNP rs10248565 in HDAC9 as a novel genomic aberration biomarker of lung adenocarcinoma in non-smoking women. Journal of biomedical science 2014; $21: 24$. http:// dx.doi.org/10.1186/1423-0127-21-24

[11] CHAN LW-C, NGO CH-C, WANG F, ZHAO MY, ZHAO $M$, et al. Disease-Specific Target Gene Expression Profiling of Molecular Imaging Probes: Database Development and Clinical Validation. Molecular imaging 2014; 13: 1-12.

[12] KABBOUT M, GARCIA MM, FUJIMOTO J, LIU DD, WOODS D, et al. ETS2 Mediated Tumor Suppressive Function and MET Oncogene Inhibition in Human Non-Small 
Cell Lung Cancer. Clinical Cancer Research 2013; 19: 3383 3395. http://dx.doi.org/10.1158/1078-0432.CCR-13-0341

[13] GAUTIER L, COPE L, BOLSTAD BM, IRIZARRY RA. affy-analysis of Affymetrix GeneChip data at the probe level. Bioinformatics 2004; 20: 307-315. http://dx.doi.org/10.1093/ bioinformatics/btg 405

[14] LU T-P, LAI L-C, TSAI M-H, CHEN P-C, HSU C-P, et al. Integrated analyses of copy number variations and gene expression in lung adenocarcinoma. PloS one 2011; 6: e24829. http://dx.doi.org/10.1371/journal.pone.0024829

[15] SCHARPF RB, IRIZARRY RA, RITCHIE ME, CARVALHO $\mathrm{B}$, RUCZINSKI I. Using the R package crlmm for genotyping and copy number estimation. Journal of statistical software 2011; 40: 1 .

[16] GIBBS RA, BELMONT JW, HARDENBOL P, WILLIS TD, YU F, et al. The international HapMap project. Nature 2003; 426: 789-796. http://dx.doi.org/10.1038/nature02168

[17] SARASQUETE ME, GARCIA-SANZ R, MARIN L, ALCOCEBA M, CHILLÓN MC, et al. Bisphosphonate-related osteonecrosis of the jaw is associated with polymorphisms of the cytochrome P450 CYP2C8 in multiple myeloma: a genome-wide single nucleotide polymorphism analysis. Blood 2008; 112: 2709-2712. http://dx.doi.org/10.1182/blood2008-04-147884

[18] SMYTH GK. Limma: linear models for microarray data. Springer, 2005: 397-420.

[19] HOMMEL G. A stagewise rejective multiple test procedure based on a modified Bonferroni test. Biometrika 1988; 75: 383-386. http://dx.doi.org/10.1093/biomet/75.2.383

[20] PURCELL S, NEALE B, TODD-BROWN K, THOMAS L, FERREIRA MA, et al. PLINK: a tool set for whole-genome association and population-based linkage analyses. The American Journal of Human Genetics 2007; 81: 559-575. http://dx.doi.org/10.1086/519795

[21] SHI H, MEDWAY C, BROWN K, KALSHEKER N, MORGAN K. Using Fisher's method with PLINK ,LD clumped'output to compare SNP effects across Genome-wide Association Study (GWAS) datasets. International journal of molecular epidemiology and genetics 2011; 2: 30 .

[22] PENG G, LUO L, SIU H, ZHU Y, HU P, et al. Gene and pathway-based second-wave analysis of genome-wide association studies. European Journal of Human Genetics 2010; 18: 111-117. http://dx.doi.org/10.1038/ejhg.2009.115

[23] LI C, LI X, MIAO Y, WANG Q, JIANG W, et al. SubpathwayMiner: a software package for flexible identification of pathways. Nucleic acids research 2009; 37: e131-e131. http:// dx.doi.org/10.1093/nar/gkp667

[24] BAOLIN L, BO H. HPRD: a high performance RDF database. Springer, 2007: 364-374.

[25] KOHL M, WIESE S, WARSCHEID B. Cytoscape: software for visualization and analysis of biological networks. Springer, 2011: 291-303.

[26] LEITE TC, COELHO RG, SILVA DD, COELHO WS, MARINHO-CARVALHO MM, et al. Lactate downregulates the glycolytic enzymes hexokinase and phosphofructokinase in diverse tissues from mice. FEBS letters 2011; 585: 92-98. http://dx.doi.org/10.1016/j.febslet.2010.11.009
[27] TOPHAM MK, PRESCOTT SM. Mammalian diacylglycerol kinases, a family of lipid kinases with signaling functions. Journal of Biological Chemistry 1999; 274: 11447-11450. http://dx.doi.org/10.1074/jbc.274.17.11447

[28] OPARINA NY, SNEZHKINA A, SADRITDINOVA A, VESELOVSKII V, DMITRIEV A, et al. Differential expression of genes that encode glycolysis enzymes in kidney and lung cancer in humans. Russian Journal of Genetics 2013; 49: 707-716. http://dx.doi.org/10.1134/S1022795413050104

[29] MOLATORE S, LIYANARACHCHIS, IRMLER M, PERREN A, MANNELLI M, et al. Pheochromocytoma in rats with multiple endocrine neoplasia (MENX) shares gene expression patterns with human pheochromocytoma. Proceedings of the National Academy of Sciences 2010; 107: 18493-18498. http://dx.doi.org/10.1073/pnas.1003956107

[30] WEBB PM, BAIN CJ, PURDIE DM, HARVEY PW, GREEN A. Milk consumption, galactose metabolism and ovarian cancer (Australia). Cancer Causes \& Control 1998; 9: 637-644. http://dx.doi.org/10.1023/A:1008891714412

[31] TACHIBANA H, TANIGUCHI K, USHIO Y, TERUYA K, OSADA K, et al. Changes of monosaccharide availability of human hybridoma lead to alteration of biological properties of human monoclonal antibody. Cytotechnology 1994; 16: 151-157. http://dx.doi.org/10.1007/BF00749902

[32] MARTIN-BERNABE A, CORTES R, LEHMANN SG, SEVE M, CASCANTE M, et al. Quantitative Proteomic Approach to Understand Metabolic Adaptation in Non-Small Cell Lung Cancer. Journal of proteome research 2014. http://dx.doi. $\operatorname{org} / 10.1021 / \operatorname{pr} 500327 \mathrm{v}$

[33] TANIGUCHI CM, EMANUELLI B, KAHN CR. Critical nodes in signalling pathways: insights into insulin action. Nature Reviews Molecular Cell Biology 2006; 7: 85-96. http:// dx.doi.org/10.1038/nrm1837

[34] PESSON M, EYMIN B, DE LA GRANGE P, SIMON B, CORCOS L. A dedicated microarray for in-depth analysis of premRNA splicing events: application to the study of genes involved in the response to targeted anticancer therapies. Molecular cancer 2014; 13: 9. http://dx.doi.org/10.1186/1476-4598-13-9

[35] LU Y, LEMON W, LIU P-Y, YI Y, MORRISON C, et al. A gene expression signature predicts survival of patients with stage I non-small cell lung cancer. PLoS medicine 2006; 3: e467. http://dx.doi.org/10.1371/journal.pmed.0030467

[36] MURUGAN AK, DONG J, XIE J, XING M. Uncommon GNAQ, MMP8, AKT3, EGFR, and PIK3R1 mutations in thyroid cancers. Endocrine pathology 2011;22:97-102. http:// dx.doi.org/10.1007/s12022-011-9155-X

[37] LEVINE DA, BOGOMOLNIY F, YEE CJ, LASH A, BARAKAT $\mathrm{RR}$, et al. Frequent mutation of the PIK3CA gene in ovarian and breast cancers. Clinical Cancer Research 2005; 11: 2875-2878. http://dx.doi.org/10.1158/1078-0432.CCR-04-2142

[38] XU Y, LUO S, LIU Y, LI J, LU Y, et al. Integrated gene network analysis and text mining revealing PIK3R1 regulated by miR127 in human bladder cancer. European journal of medical research 2013; 18: 29. http://dx.doi.org/10.1186/2047-783X$\underline{18-29}$

[39] LOGUE MW, BALDWIN C, GUFFANTI G, MELISTA E, WOLF EJ, et al. A genome-wide association study of 
post-traumatic stress disorder identifies the retinoid-related orphan receptor alpha (RORA) gene as a significant risk locus. Molecular psychiatry 2012; 18: 937-942. http://dx.doi. org/10.1038/mp.2012.113

[40] GUAN H, ZHANG P, LIU C, ZHANG J, HUANG Z, et al. Characterization and functional analysis of the human microRNA let-7a2 promoter in lung cancer A549 cell lines. Molecular biology reports 2011; 38: 5327-5334. http://dx.doi. org/10.1007/s11033-011-0683-8

[41] SHI Y, CAO J, GAO J, ZHENG L, GOODWIN A, et al. Retinoic acid-related orphan receptor- $\alpha$ is induced in the setting of DNA damage and promotes pulmonary emphysema. American journal of respiratory and critical care medicine 2012; 186: 412-419. http://dx.doi.org/10.1164/rccm.201111-2023OC

[42] NEURATH MF, FINOTTO S. The emerging role of T cell cytokines in non-small cell lung cancer. Cytokine \& growth factor reviews 2012; 23: 315-322. http://dx.doi.org/10.1016/j. cytogfr.2012.08.009

[43] ADAMSKY K, ARNOLD K, SABANAY H, PELES E. Junctional protein MAGI-3 interacts with receptor tyrosine phosphatase $\beta$ (RPTP $\beta$ ) and tyrosine-phosphorylated proteins. Journal of cell science 2003; 116: 1279-1289. http://dx.doi. org/10.1242/jcs.00302

[44] WU Y, DOWBENKO D, SPENCER S, LAURA R, LEE J, et al. Interaction of the tumor suppressor PTEN/MMAC with a PDZ domain of MAGI3, a novel membrane-associated guanylate kinase. Journal of Biological Chemistry 2000; 275: 21477-21485. http://dx.doi.org/10.1074/jbc. M909741199

[45] MATSUDA S, KITAGISHI Y. MAGI Scaffolding Molecules Involved in Cancer Cell Signaling. Journal of Carcinogenesis \& Mutagenesis 2013; S7: 005.

[46] TANG J-M, HE Q-Y, GUO R-X, CHANG X-J. Phosphorylated Akt overexpression and loss of PTEN expression in non-small cell lung cancer confers poor prognosis. Lung cancer 2006; 51: 181-191. http://dx.doi.org/10.1016/j. lungcan.2005.10.003

[47] KATOH M. WNT/PCP signaling pathway and human cancer (review). Oncology reports 2005; 14: 1583. http://dx.doi. org/10.3892/or.14.6.1583 